\title{
O DESIGN PARA A EXPERIÊNCIA NA CONSTRUÇÃO DO LUGAR TURÍSTICO: POSSIBILIDADES E LIMITAÇÕES
}

Mariana Valcacio Araújo Pereira

Universidade Federal de Pernambuco

marianavalcacio@gmail.com

Ney Brito Dantas

Universidade Federal de Pernambuco

ney.dantas@gmail.com

Resumo: A relação da cidade com design, cultura e turismo tem proporcionado uma grande expansão da atividade turística nas últimas décadas. Destinos turísticos que procuram distinguir-se cada vez mais dos seus numerosos concorrentes têm se voltado para a sua identidade como um meio de diferenciação. Esse ponto também abarca questões sociais, pois o turismo gera renda e empregos através da interação social no lugar. O turista pós moderno busca a ressignificação da sua vivência em um lugar, dessa forma as suas atividades ao longo dos anos em viagens têm se tornado mais ativas, ao passo que a sua procura é por uma experiência autêntica e particular. Assim o branding de cidade, o placemaking e a gamificação são delimitados nesse estudo como ferramentas estratégica para promover o design para a experiência turística na cidade.

Palavras-chave: Turismo, Experiência, Design, Criatividade.

Abstract: The city's relationship with design, culture and tourism has provided a major expansion of tourism in recent decades. Touristic destinations that seek to be distinguished from its numerous competitors have turned to their identity as a way of differentiation. This aspect also covers social issues, since tourism generates income and jobs through social interaction in the place. The post-modern tourist seeks to reframe your experience in one place, that way its activities over the years on trips have become more active, while their demand is for an authentic and unique experience. Thus, city branding, placemaking and gamification are defined in this study as a strategic tool to promote design for the tourist experience.

Keywords: Tourism, Experience, Design, Creativity. 


\section{INTRODUÇÃO}

O turismo é um fenômeno social que surgiu a partir das viagens realizadas por jovens da aristocracia européia no século XVIII, como atividade organizada no século XIX e como fenômeno de massa a partir da Segunda Guerra Mundial (RICCO, 2012), se estabelecendo como uma prática de lazer do indivíduo. Assim, com o crescimento das cidades, a globalização e o desenvolvimento do setor de serviços que eleva a um novo patamar a economia, o turismo é uma das atividades que mais se expande no mundo. Nesse sentido, a cultura no domínio do turismo foi elemento primordial ao intensificar viagens turísticas no final do século XX (DIAS, 2006 apud RICCO, 2012). Logo, o turismo cultural, sendo ele constituído por hábitos culturais, propicia o dialogo entre as diferentes sociedades (RICCO, 2012).

O desenvolvimento do turismo cultural, como o conhecemos atualmente, esteve sempre baseado na troca entre capital cultural e econômico articulado a partir de uma economia voltada para questões simbólicas. O turismo criativo, por outro lado, está ligado as formas ainda mais flexíveis de troca de capital social, relacional e intelectual dentro de um sistema que vai desde uma superestrutura até uma a interação com a comunidade receptora. Dentre estas formas flexíveis, o crescimento do turismo criativo está particularmente ligado ao surgimento da co-criação como motor da demanda turística e de uma economia da experiência, pois atualmente a construção da cidade se dá de maneira colaborativa (SILVA, 2014). Nesse contexto, As cidades se transformam, buscando suprir necessidades que vão além do cenário local (BICUDO, 2007), pois na contemporaneidade, cada lugar é constituído continuamente de forma global e local (SANTOS, 1996 apud BESSA, 2011). Assim, o desenvolvimento de uma nova forma de economia, aliada a um capital relacional torna-se imprescindível, ao passo que nas ações reflexivas da pós-modernidade o ser humano precisa de momentos de lazer que o retiram da sua realidade e proporcionam a ressignificação do seu cotidiano e de suas experiências passadas (PEZZI E SANTOS, 2012). Essa atividade provoca o turista contemporâneo a ser ativo na própria vivência.

Turismo criativo é uma extensão do turismo cultural (RICHARDS, 2011), pois os turistas se envolvem ativamente na construção lúdica do lugar e interagem com a população local, ocasionando em uma maior permanência no destino e em um relacionamento significativo com sua comunidade (RICHARDS E RAYMOND, 2000). Nesse cenário, a criatividade gera uma atmosfera de acontecimentos para o turista, alimenta o auto-conhecimento por parte de todos, ativa laços culturais entre turistas e locais, como também inova na produção de artefatos turísticos (RICHARD E RAYMOND, 2000). Os principais fatores qualitativos do turismo criativo, segundo esse estudo, podem ser pontuados como:

- O crescente interesse na cultura popular, ou na "cultura cotidiana" do destino;

- Consumo progressivo do patrimônio imaterial do lugar, como as manifestações culturais que vão além museus e monumentos;

- O papel das artes no turismo cultural;

- O aumento da relação entre o turismo e criatividade. 
Seguindo essa linha de pensamento, o desenvolvimento da economia criativa oferece muitas e novas oportunidades para o desenvolvimento do turismo, do marketing de lugares e consequentemente do urbanismo. Enquanto a relação entre cultura e turismo está bem desenvolvida, as indústrias criativas possibilitam um guarda-chuva mais amplo, indo além dos recursos disponíveis para o turismo cultural, que são em grande parte relacionados ao patrimônio construído. Os principais ativos das indústrias criativas relacionadas ao turismo estão baseados em conhecimentos e habilidades.

O turismo criativo aparece, portanto, como uma opção chave para o desenvolvimento econômico de destinos turísticos, pois ele responde à necessidade de reinvenção constante do turismo bem como à necessidade dos destinos se reinventarem em um mercado saturado. Além disso, essa nova forma de turismo atende ao desejo de turistas que buscam ofertas de experiências mais dinâmicas, gratificantes e significativas, motivando o retorno aos destinos visitados. Como também, o turismo criativo atrai a classe criativa como visitante, o que contribui para o aumento de uma atmosfera criativa na cidade, aumentando o potencial do lugar enquanto atividade turística.

$\mathrm{Na}$ contemporaneidade, vivenciar um espaço urbano não se constitui em umainteração pessoal, pois durante a construção dos significados de uma cidade os meios midiáticos interferem ativamente na sua concepção e na sua derrocada (SILVA, 2014). O produto turístico em territórios criativos transforma-se, assim, em uma grande instalação interativa, que não se restringe aos locais de visitação e trilhas. Isto quer dizer que não haverá uma ruptura da experiência de visitação quando o visitante retorna ao seu lugar de origem. Através de uma variedade de mídias, os visitantes devem continuar interagindo remotamente com o destino turístico criativo. Poderão tanto ver e ouvir o que está acontecendo no destino como participar de suas atividades e gerar novos conteúdos mesmo depois de voltar para a sua origem. Deverá ainda ser estimulado o desejo de retorno do turista ao destino, uma vez que haverá a certeza de novas experiências a cada estadia. Compreendendo que o ciberespaço é um apêndice da cidade, as interações virtuais podem ser reconstituídas no lugar real (CASTELLO, 2010).

\section{DESENVOLVIMENTO}

A evolução da economia se constituiu em uma passagem do serviço para a experiência, no qual o consumidor vivencia situações memoráveis (PINE E GUILMORE, 1988 apud FREIRE, 2009). Nesse sentindo às emoções são coadjuvantes na construção dessa memória, pois constituem a evidência das experiências a partir da tangibilidade das lembranças (GRABURN,1989 apud PEZZI E VIANNA, 2015). A experiência turística é um evento passado forte o suficiente para entrar na memória (LARSEN E MOSSBERG, 2007). Assim, na idealização do lugar turístico, o design não molda a experiência pois a mesma é constituída pelo próprio indivíduo, ao passo que cada experiência é particular. Nesse ótica, ele estimula a experiência emocional já existente (FREIRE 2009) que se formulará como memória mais adiante, materializada em lembrança. 
Diante disso, o design para a experiência se insere como uma abordagem projetual de um cenário, que se utiliza de métodos, modelos, teorias, procedimentos, processos, ferramentas e estratégias que envolvem o usuário no desenvolvimento de suas emoções, sentimentos e consequentemente, memórias. Assim, esse estudo promove o paralelo de três aplicações do design para a experiência turística: Branding de Cidade, Placemaking e Gamificação.

\subsection{Branding de Cidade}

Branding de cidade abrange a atuação e a importância da gestão da cidade na construção da identidade do lugar e do seu reflexo para a sociedade. No contexto do turismo criativo, essa estratégia é utilizada pelo design como forma de delimitar guias e diretrizes para a concepção de cenários promovendo uma melhor experiência turística na cidade. Falar de uma encenação não significa necessariamente um estratagema, mas a facilidade do acesso à oferta, tornando as coisas mais proeminentes e consistentes, proporcionando à chave da interpretação do lugar pelos turistas. As experiências mais fortes são também muitas vezes as mais espontâneas e naturais (FUX, 2014). Abordagens em turismo criativo proporciona, sem dúvida, potencial para o desenvolvimento de novas narrativas, significados e identidades em destinos turísticos (RICHARDS, 2011). É necessário ressaltar também, que nesse sentido, a experiência turística não se limita à um evento concreto que se produz na destinação. Ela começa bem antes, notadamente na fase de "inspiração"e "imaginação", que cria emoções positivas e prazerosas, que se prolongam depois no compartilhamento e exploração das lembranças (FUX, 2014).

Brand, traduzido para o português como "marca", além de um sinal impresso se configura como uma forma de identificação. A marca abrange esses conceitos, pois ela reúne os elementos tangíveis como um projeto gráfico, essencial na identificação de um produto ou serviço. Como também, possui aspectos intangíveis, sendo esses seus valores (SILVA, 2014). Sendo a marca, então, um conjunto das suas crenças e de seus atributos físicos, sociais (SIMÕES e DIBB, 2001). Assim, é possível inferir que o branding deve ser aplicado de forma eficaz na cidade, pois a imagem da cidade é comunicada e não somente promovida (KAVARATZIS 2004). Logo, ela é um dos primeiros canais de comunicação com o turista, pois a marca de um lugar conta a história desse lugar.

A experiência turística parte da comunicação da imagem da cidade, que desperta o início de uma viagem e a vontade do retorno. É imprescindível destacar que a imagem da cidade está diretamente relacionada com a sua identidade, pois identidade resulta de uma construção social (CUCHE, 1999). A questão da identidade torna-se fundamental para a cidade contemporânea que surge no contexto local e global (BICUDO, 2007). Logo, deve-se levar, também, em consideração que em um lugar que se propõe ao turismo criativo deve ser desenvolvida a gestão da identidade, pois num mesmo lugar há várias identidades, essas que se diferenciam, se reconhecem e se transmutam em outras. A formação dos lugares se dá, na verdade, pela concepção da identidade dos espaços no tempo, sendo a comunicação e o design cada vez mais parte constituinte de do processo de planejamento urbano (BICUDO,2007). 
Torna-se relevante salientar que ao levar o conceito de branding para a sua implementação na cidade, pode conter um equívoco na sua utilização, pois a partir do momento que o lugar é reconhecido com uma marca, um "brand" ele é entendido com uma negócio lucrativo (BICUDO, 2007). Nesse sentido, é importante frisar que há limitações do conceito de branding para cidades, pois não se pode esquecer que esse é um conceito que parte da esfera empresarial e o que se é trabalhado no contexto da cidade é a promoção do valor e um modelo de gestão. Consequentemente, o interesse coletivo deve ser ressaltado (DUARTE E JÚNIOR 2007). Outro ponto a se levantar é a transformação da cidade em mercadoria, pois tal processo, levado às últimas consequências, faria com que seus moradores ficassem cada vez mais sedentos de novidades, e transformaria os "espaços em pastiches, clichês superficiais de uma idéia de cidade" (SÁNCHEZ GARCIA, 1999 apud DUARTE E JÚNIOR, 2007). Assim, branding é um conceito visto como importante, mas nem sempre entendido e aplicado de maneira eficaz (KAVARATZIS, 2004).

\subsection{Placemaking}

A experiência do turismo em um lugar promove uma ressignificação ao viajante, modificando a sua percepção do local visitado e a do local que habita. 0 placemaking é uma ferramenta que auxilia na vivência e na construção do lugar turístico a partir da interação do visitante no espaço. Ele é compreendido também como revitalização, renovação urbana, regeneração, dentre outros sinônimos que abarcam a preservação histórica do espaço. Placemaking são espaços públicos que estimulam interações entre as pessoas em si e entre as pessoas e a cidade, se configurando assim como um conceito e uma ferramenta (HEEMANN E SANTIAGO, 1999). Placemaking criativo integra a comunidade, a cultura e o desenvolvimento econômico (VAZQUEZ, 2012) e leva as pessoas e as organizações a se unirem na criação de uma vida melhor, a partir da identidade e da trajetória histórica do lugar (BORRUP, 2016). Nesse sentido o design para a experiência tangencia o design urbano e social, pois se estabelece como um guia dessas atividades na cidade, buscando interagir com outros domínios, principalmente artísticos, para promover o bem estar no lugar. Como também, ele se utiliza de outras abordagens para a complementação da sua interferência no espaço. Assim, o placemaking pode variar entre diversos tipos de lugares, para diversas atividades, sendo construídas a partir da cultura.

A essência do turismo criativo parece encontrar-se em atividades e experiências relacionadas à auto-realização e auto-expressão através do qual os turistas se tornam co-intérpretes e co-criadores à medida que desenvolvem suas habilidades criativas (RICHARDS, 2011). Logo, ele gera uma democratização da sociedade. Assim, ressalta-se que a co-criação no placemaking é o ativador da criatividade e da interação no espaço, propiciando ao viajante uma vivencia na cidade e o inserindo na construção da identidade do lugar. Colocar o turista e o residente como parte do processo gera o envolvimento de diferentes formações, experiências, interesses e papeis (GAUDIO 2014 apud SANDERS; BRANDT; BINDER, 2010). Entende-se então que o turismo criativo introduz o Participatory Design a partir do seu elemento de co-criação. Assim, o evolvimento nessa dinâmica proporciona a compreensão da importância dos participantes, pois cada um deles tem uma voz por ser especialista no 
que faz. As ideias de design nascem, assim, da colaboração dessa multiplicidade (SANOFF 2007 apud DEL GAUDIO 2014).

Dessa forma, o visitante, junto aos residentes, se torna um construtor da sua própria experiência turística, o que fortifica o conceito de que cada experiência é particular. Essa interação do viajante com a cidade estabelece um elo entre esses dois elementos, fomentando as suas memórias no destino turístico, a partir da identidade que se construiu e se ressignificou no local, como também nas relações que se estabeleceram. O lugar turístico, construído a partir do placemaking, além de ser produzido de forma cooperativa, é um espaço compartilhado (BORRUP, 2016). Partindo dessa visão, não se deve compreender que a característica global que o placemaking proporciona para o lugar leva a territorialização turística. O lugar turístico nesse contexto, não é apropriado, mas sim, dividido harmonicamente.

É relevante destacar que o design como coordenador da experiência turística e consequentemente das trocas culturais, deve acompanhar e não só iniciar o processo de partilha entre turistas e residentes. $\mathrm{O}$ acompanhamento gera a reflexão e pouco a pouco a própria transformação do cenário que seguem as relações e interações estabelecidas. Nesse contexto, se uma cenário se mantém constante pode ocorrer uma massificação desse lugar, ou seja, ele será tumultuado de pessoas que não buscam serem ativadoras do processo, pois o turismo de massa é passivo. $E$, não havendo assim relações que o preencham, e se conectem com ele, o placemaking será mais um espaço de imitação e não de ressignificação. Nesse sentido, as pessoas envolvidas nesse processo ativo de construção do lugar turístico criativo a partir da cultura e das artes, placemakers, devem ser colaborativas, compadecidas, competentes culturalmente, complacentes, guias e sustentáveis (VAZQUEZ, 2012).

Outra limitação existente para o placemaking é a descrença que profissionais das artes são pessoas de negócios e podem ser influenciadores em políticas urbanas (VAZQUEZ, 2012). Dessa forma, é necessário que haja uma união entre os profissionais de cultura em prol da desmistificação. Contudo, o próprio placemaking pode ser um caminho para elevar o status desses profissionais da economia criativa, ao demonstrar que as artes levam oportunidades econômicas às comunidades (VAZQUEZ, 2012).

\subsection{Gamificação}

$\mathrm{Na}$ construção da experiência turística, o design se estabelece como uma ferramenta de projeção de cenários. Nesse sentido, a Gamificação de espaços se configura como um instrumento criativo de modelagem do lugar turístico.

A teoria do Design-Driven Innovation (VERGANTI, 2009) sugere à conjunção de inovações de significados com inovações tecnológicas para a geração de propostas de alto impacto de transformação. Ela contribui para a transformação de lugares turísticos quando propõe uma inovação de significado, sendo eles potencializados por intermédio de uma inovação tecnológica: a gamificação. Esta conjunção entre significado e tecnologia, como demonstra o autor, tem capacidade para produzir um lugar com características únicas, para recriar modelos turísticos de negócios e construir novos mercados que vão ao encontro de necessidades ainda inexistentes ou não 
atendidas, se reconfigurando como novos produtos e serviços turísticos, instituindo novos valores e criando novos significados.

A proposta que se faz de gamificação de lugares parte do entendimento que determinados espaços urbanos são fundamentais para a dinâmica turística das cidades. Para ativar espaços e transformá-los em áreas animadas e criativas, é necessário que profissionais do turismo, designers e arquitetos saibam combinar o lúdico e o ambiente urbano para melhorar à experiência da vida cotidiana, dos grandes impactos turísticos, econômicos e sociais ofertando assim vivências além das tradicionais.

A fim de refletir sobre a natureza do jogo urbano, é preciso esclarecer a diferença entre os termos brincadeiras e jogos. O jogo baseia-se no pressuposto de que brincar é a base de um jogo, e que não pode existir um sem o outro. Ele é uma atividade ou ocupação voluntária, exercida dentro de certos e determinados limites de tempo e de espaço, segundo regras livremente consentidas, mas absolutamente obrigatórias, dotada de um fim em si mesmo, acompanhado de um sentimento de tensão e de alegria e de uma consciência de ser diferente da vida cotidiana (HUIZINGA, 2000). O brincar e o jogar são vistos como práticas humanas no espaço. A brincadeira pode ser vista como um aspecto de jogos, bem como os jogos como uma forma de brincadeira (BRATHWAITE E SCHREIBER, 2009). Apesar dos conceitos próximos um do outro, na visão de Brathwaite e Schreiber o importante é a forma que eles se relacionam e não a definição de cada um isoladamente. A definição de jogo, portanto, concentra-se em quatro maneiras interrelacionadas em que o comportamento lúdico pode ser experimentado como uma fuga de outros aspectos da vida cotidiana na cidade:

- Jogo envolve ações que são livres;

- Existem condições de contorno e as regras;

- Jogo envolve tipos específicos de atividades através das quais as pessoas testam e expandem limites;

- Jogo na cidade, muitas vezes, possibilita envolver encontros com estranhos.

Projetar jogos que não são apenas jogos, por terem um valor além do entretenimento, é conhecido como gamification. Gamification ou gamificação, em tradução livre, é a utilização dos elementos de jogos em um contexto de não-jogo (DETERDING et al., 2011). Ou seja, ela aplica mecanismos de jogos à resolução de problemas em contextos reais, com o objetivo de incrementar a participação e promover o engajamento. Os projetos que utilizam essa abordagem, muitas vezes, dão origem a um comportamento lúdico.

Através dos elementos presentes nos jogos é possível criar um sistema com propósito subjacente além da diversão, contribuindo para aumentar a atratividade turística da cidade e criar novas conexões com as pessoas. Eles podem contribuir ativamente no que se refere a encorajar turistas e residentes a adotar determinados comportamentos ou tornar mais agradáveis tarefas consideradas tediosas ou complexas. A partir de três elementos básicos do design para o ambiente urbano 
(pessoas, artefatos e contextos), é proposto nove áreas resultantes das interações entre estes elementos (LOVE 2002):

- Pessoa

- Objetos

- Contextos

- Interações pessoa - pessoa

- Interações objeto - objeto

- Interações pessoa - objeto

- Interações pessoa - contexto

- Interações objeto - contexto

- Interações que envolvam pessoa, objeto e contexto em conjunto

Através das áreas elencadas por Love (2002) é possível identificar a relação entre o design e outras áreas disciplinares. Neste ponto, a gamificação inclui uma série de conceitos psicológicos, especialmente em relação a motivação, comportamento e personalidade. A compreensão profunda desses conceitos é uma das chaves mais importantes para adequá-los à sua implantação.

Contudo, é importante destacar que um ponto comum entre a limitação da gamificação e do placemaking é a transformação dos lugares em espaços clichês e reproduzíveis massivamente. Como também a da criação de um cenário artificial dentro da própria cidade, restringindo o turista a vivência do jogo. Delimitar até que ponto a gamificação é uma ferramenta de guia para viagem e como ela se configura parte da atuação do design no projeto para a experiência turística.

\section{CONCLUSÃO}

O turismo criativo aliado ao design de experiência se torna um fator potencializador da transformações inovadoras no espaço urbano para experiência do turista contemporâneo. Por conseguinte, o design, como formulador de ações sistêmicas (CARDOSO 2012) propõe narrativas que visam inserir à criatividade na gestão do destino turístico. Logo, a criatividade envolvida no turismo criativo também não se limita a um único ator, como os próprios turistas, mas envolve a interação criativa dos produtores, consumidores, políticos e paisagens que pretendem desenvolver a criatividade incorporada no turismo de experiência (RICHARDS, 2011). Nesse cenário, é imprescindível que o design saiba contextualizar suas ferramentas, percebendo quais são as possibilidades e os limites de atuação das mesmas para determinadas abordagens.

Dessa maneira, o turismo criativo implica, não necessariamente, nos turistas precisarem ser criativamente envolvidos, mas que o próprio destino precisa se tornar mais criativo no projeto de suas experiências características. Isto significa que o destino precisa refletir cuidadosamente sobre os aspectos da criatividade que estão ligados ao lugar, pois os mesmos dão aos turistas criativos uma motivação específica para visitar. (RICHARDS e RAYMOND, 2000 apud RICHARDS, 2011). Torna-se visível o 
papel do branding de cidade, do placemaking e da gamificação no espaço compondo a experiência turística criativa.

O branding de cidade voltado para o turismo criativo, se insere como uma abordagem junto a gestão da cidade que visa a construção da imagem do destino turístico a partir de estratégias criativas. O placemaking, como estratégia criativa de interações do espaço urbano do destino turístico, proporciona o compartilhamento de vivências entre o visitante e o habitante, colocando o turista como um transformador do lugar turístico. A gamificação, então, se insere como um promotor do engajamento entre o turista e os habitantes com o entorno, aumentando a interação a partir da dinâmica de games. Destaca-se por fim, que essas ações do campo do design visam atingir a imagem da cidade na pré- visitação, na visitação e na pós-visitação do viajante no destino turístico.

\section{REFERÊNCIAS}

BRATHWAITE, Brenda; SCHREIBER, lan. Challenges for Game Designers. Charles River Media, 2009

BESSA, Altamiro. A construção das paisagens turísticas nos descaminhos da Estrada Real. 2011. 280 f. Tese (Doutorado) - Faculdade de Arquitetura e Urbanismo, Universidade de São Paulo.

BORRUP, Tom. Creative Placemaking: Arts, and Culture as a Partner in Community Revitalization. In: Fundamental of Arts Management. (Org) University Of Massachusetts. 2016. Disponível em < http://creativecommunitybuilders.com/wpcontent/uploads/Borrup-Creative-Placemaking-2016-UMASS.pdf>

BICUDO, Marcelo. Place branding e Place Making. Epigram. <http://www.epigram.com.br/wp-content/uploads/2009/10/place_branding.pdf>. Acesso em 10 jun. 2016

CARDOSO, Rafael. Design para um mundo complexo. São Paulo: Cosac Naify, 2012.

CASTELLO, Lineu, Replicar. Revitalizar. Repensar. In: I Encontro Nacional da Associação Nacionalde Pesquisa e Pós-Graduação em Arquitetura e Urbanismo. Rio De Janeiro. 2010.

COSTA, Jean. A imagem da marca: um fenômeno social. São Paulo: Rosari, 2011.

CUCHE, Denys. A noção de cultura das ciências sociais. Bauru: EDUSC, 1999.

DEL GAUDIO, Chiara. Design Participativo e Inovação Social: a influência dos fatores contextuais. 2014. Tese (Doutorado) - Pontifícia Universidade Católica do Rio de Janeiro, Curso de Pós-Graduação em Design.

DETERDING, Sebastian; DIXON, Dan; KHALED, Rilla. Gamification: Toward a definition. Chi 2011, p. 12-15, 2011.

DIAS, Reinaldo. Turismo e patrimônio cultural - recursos que acompanham o crescimento das cidades. São Paulo: Saraiva, 2006. 
DUARTE, Fábio; JÚNIOR, Sérgio. Cidade à venda. Reflexões sobre o marketing urbano. RAP.Vol.41,N.2 2007.

FREIRE, Karine (2009) Reflexões sobre o conceito de design de experiências. Strategic Design Research Journal. Vol. 2, N.1, Pag 37-44, 2009.

FUX, Willy (2014) Designer une expérience touristique en dix points clés. Revue Espaces. N.321, pag 16-21, 2014.

GRABURN, Nelson .Turismo, el viaje sagrado; In: SMITH, Valene (ed) Anfitriones e invitados. Antropología del turisme. Madrid, 1989

HEEMANN, Jenifer; SANTIAGO, Paola. Guia do Espaço Público para inspirar e transformar. Brasil: Conexão Cultural; Bela Rua, 1999. Disponível na internet por http em: <http://www.placemaking.org.br/home/o-que-e-placemaking/guia-do-espacopublico/ >. Acesso em 10 jun. 2016

HUIZINGA, Johan. Homo Ludens. São Paulo: Editora Perspectiva, 2000

KAVARATZIS, Michalis (2014) From city marketing to city branding: Towards a theoretical framework for developing city brands. Place Branding. Vol. 1, N.1, pag 5873, 2014.

LARSEN, Svein; MOSSBERG, Lena (2007) Editorial: The Diversity of Tourism Experiences. Scandinavian Journal Of Hospitality And Tourism, Vol. 7, N.1, 1-6, 2007

LOVE, Terence. Constructing a coherent cross-disciplinary body of theory about designing and designs: some philosophical issues. International Journal of Design Studies, 23(3), pp. 345-361, 2002.

PEZZI, Eduardo; VIANNA, Silvio. (2015) A Experiência Turística e o Turismo de Experiência: Um estudo sobre as dimensões da experiência memorável. Turismo em Análise.Vol. 26, N.1, 2015.

PEZZI, Eduardo; SANTOS, Rafael, A experiência turística e o turismo de experiência: aproximações entre a antropologia e o marketing. In: SEMINÁRIO DE PESQUISA DEM TURISMO DO MERCOSUL. Caxias do Sul. 2012.

PINE, Joseph; GILMORE, James. (1998). Welcome to the experience economy. Harvard Business Review. Vol. 76, N.4. Pag 97-105, 1998.

RICCO, Adriana. O turismo como fenômeno social e antropológico. Turismo, Espaço e Estratégias de Desenvolvimento Local. João Pessoa, 2012.

RICHARDS, Greg (2011) Creativity and Tourism: The State of the Art. Annals of Tourism Research.Vol 1, N.4, pag 1225 - 1253, 2011.

RICHARDS, Greg; RAYMOND, Crispin. (2000). Creative tourism. ATLAS News, Vol. 23, pag 16-20.

RIZZO, Francesca. Strategie di co-design. Teorie, metodi e strumenti per progettare con gli utenti. Milano: Francoangeli Ed., 2009.

SÁNCHEZ GARCIA, F. Buscando um lugar ao sol para as cidades: o papel das atuais políticas de promoção urbana. In: Revista Paranaense de Geografia, Associação dos Geógrafos Brasileiros, N. 4, 1999. Disponível em:

<www.agbcuritiba.hpg.ig.com.br/Revistas/Rpg3/4fernanda.htm>. 
SANDERS, Elizabeth et all. A framework for organizing the tools and techniques of participatory design. In: PARTICIPATORY DESIGN CONFERENCE. Sydney. 2010.

SANOFF, Henry (2007) Editorial - Special issue on participatory design. Design Studies. Vol. 28. N. 3, Pag. 213-215, 2007.

SANTOS, Milton. A natureza do espaço. São Paulo: Hucitec, 1996.

SILVA, Elisangela. Olhe bem a cidade: Design emocional, place branding e a marca de belo horizonte. 2014. 122f. Dissertação (Mestrado) - Universidade do Estado de Minas Gerais, Curso de Pós-Graduação em Design.

SIMOES, Claudia; DIBB, Sally. (2001) Rethinking the brand concept: New brand orientation. Corporate Communications, Vol. 6, N. 4, pag. 217-224, 2001.

UNESCO. (2006). Tourism, Culture and Sustainable Development. United Nations Educational, Scientific and Cultural Organization. < http://unesdoc.unesco.org/images/0014/001475/147578e.pdf >. Acesso em 10 de jun. 2016

VAZQUEZ, Leonardo. Creative Placemaking: Integrating ommunity, cultural and economic development. 2012.

$<$ http://papers.ssrn.com/sol3/papers.cfm?abstract_id=2474862> . Acesso em $10 \mathrm{de}$ jun. 2016

VERGANTI, Roberto. Design-Driven Innovation. Mudando as regras da competição: a inovação radical de significado de produtos. São Paulo: Canal Certo, 2012 